\title{
Structure and Stability of Chemically Modified DNA Bases: Quantum Chemical Calculations on 16 Isomers of Diphosphocytosine
}

\author{
Abdullah G. Al-Sehemi, ${ }^{1}$ Tarek M. El-Gogary, ${ }^{2}$ \\ Karl Peter Wolschann, ${ }^{3}$ and Gottfried Koehler ${ }^{4}$ \\ ${ }^{1}$ Faculty of Science, King Khalid University, Abha, Saudi Arabia \\ ${ }^{2}$ Faculty of Science, Jazan University, Jazan, Saudi Arabia \\ ${ }^{3}$ Institute for Theoretical Chemistry, University of Vienna, 1090 Vienna, Austria \\ ${ }^{4}$ Department of Structural Biology and Biomolecular Chemistry, Max F Perutz Laboratories, \\ University of Vienna, 1030 Vienna, Austria
}

Correspondence should be addressed to Tarek M. El-Gogary; tarekelgogary@yahoo.com

Received 17 December 2012; Accepted 6 January 2013

Academic Editors: E. B. Starikov and A. Tilocca

Copyright (C) 2013 Abdullah G. Al-Sehemi et al. This is an open access article distributed under the Creative Commons Attribution License, which permits unrestricted use, distribution, and reproduction in any medium, provided the original work is properly cited.

\begin{abstract}
We studied for the first time 16 tautomers/rotamers of diphosphocytosine by four computational methods. Some of these tautomers/rotamers are isoenergetic although they have different structures. High-level electron correlation MP2 and MP4(SDQ) $a b$ initio methods and density functional methods employing a B3LYP and the new M06-2X functional were used to study the structure and relative stability of 16 tautomers/rotamers of diphosphocytosine. The dienol tautomers of diphosphocytosine are shown to be much more stable than the keto-enol and diketo forms. The tautomers/rotamers stability could be ranked as $\mathbf{P C} 3=\mathbf{P C 1}<\mathbf{P C 2}=\mathbf{P C 1 1}<\mathbf{P C 1}<\mathbf{P C 1 0}<\mathbf{P C 8}<\mathbf{P C 9}<\mathbf{P C 1 5}<\mathbf{P C 1 6}<\mathbf{P C 6} \sim$ PC7 $<$ PC13 $<$ PC4 $\sim$ PC14 $<$ PC5. This stability order was discussed in the light of stereo and electronic factors. Solvation effect has been modeled in a high dielectric solvent, water using the polarized continuum model (PCM). Consideration of the solvent causes some reordering of the relative stability of diphosphocytosine tautomers: PC3 $\sim$ PC12 $\sim$ PC2 $\sim$ PC11 $<$ PC1 $<$ PC10 $<$ PC8 $<$ PC9 $<$ PC15 $\sim$ PC16 $<$ PC13 $<$ PC6 $\sim$ PC7 PC14 $<$ PC4 PC5.
\end{abstract}

\section{Introduction}

DNA is a naturally occurring biological macromolecule, containing thousands of nucleic acid bases, and it is of prime importance in genetic determination [1]. The five nucleic acid bases, cytosine, thymine, uracil, adenine, and guanine, found in DNA and RNA control the replication of DNA, store information required to synthesize proteins, and translate this information to the protein. Tautomerism is a well-known phenomenon occurring in nucleic acid bases [2-16], in which proton transfer from the heterocyclic ring center to an exocyclic oxo- or imino- group leads to the formation of either an $-\mathrm{OH}$ or an $-\mathrm{NH}_{2}$ groups. These processes are known as keto-enol or imino-amino tautomerism, respectively. Tautomerism, a sort of isomerism, plays an important role in organic chemistry, medicinal chemistry, pharmacology, and molecular biology. Tautomerism partially explains the structure of nucleic acids and their mutations [17]. In DNA bases, tautomerization results in altered base pairing configurations or mispairing due to changes in hydrogen-bonding capabilities. DNA mutations are likely to be caused by such alterations. Cytosine is one of the building pyrimidine nucleobases of RNA. A large amount of experimental [18-34] and theoretical work [35-58] has been carried out in order to elucidate the structure of cytosine and its tautomers. Chemically modified bases have attracted extensive interest due to their numerous pharmacological, biochemical, and biological capabilities [59-62]. Replacing 
nitrogen in pyrimidine and purine DNA bases by the biological element of interest, phosphorus, may produce new synthesizable bases of special interest. Modification of cytosine base to phosphorus-containing cytosine analogues, diphosphocytosine, is a good start point in this topic. Also, their existence in many tautomeric forms, like other nucleoside bases, seems to be crucial in order to explain the mutation occurring during DNA duplication [63-66]. Searching the literatures confirms that no previous studies include all numbers of cytosine tautomers. This is the first time to include 16 isomers of cytosine. Similar to cytosine, the diphosphocytosine should also have 16 tautomers. There are many interesting questions on the diphosphocytosine tautomers concerning, for example, their relative stability order, energy criteria, proton transfer processes, electronic structure, and chemical properties. In an attempt to answer some of these questions using computational studies, some DFT methods (B3LYP, M06-2X) and $a b$ initio MP2 and MP4(SDQ) methods are chosen to study the stability order and tautomerization processes of all the possible 16 diphosphocytosine tautomers in the gas phase as well as in water. Compared to the popular B3LYP method, studies of tautomerism using the recent method M06-2X are very rare and it is worthwhile to consider them here in this work to assess their accuracy compared to MP4(SDQ) data.

Among cytosine tautomers, experimental investigations performed in gas phase, solid state, or in solution indicate that the canonic amino-oxo tautomer of cytosine is the most stable one [67]. One of our interesting computational results [67, 68] of diphosphocytosine tautomers is the reverse stability order as compared to the parent analogue, cytosine. The origin of this stability order needs to be interpreted as it is not fully discussed. One of the main objectives of this work is to investigate this behavior on the basis of the unique bonding properties of the phosphorous atom.

\section{Computational Methods}

All quantum chemical calculations were performed using the Gaussian 09 suite of programs [69]. Geometry optimizations for all tautomers have been performed using $a b$ initio density functional theory (DFT) at the B3LYP functional [70-72] and the new M06-2X functional in conjunction with the 6-31G(d) basis set. For each stationary point, we carried out a force constant harmonic frequency calculation at the same levels to characterize their nature as minima or transition states and to correct energies for zero-point energy and thermal contribution. The frequencies are scaled by a factor of 0.98 . The vibrational modes were animated using the ChemCraft program [73]. Natural charges were computed within full Natural Bond Orbital Analysis, using NBO implemented in Gaussian 09 [69]. The vibrational modes were examined by using the ChemCraft program [73]. Partial charge distributions were calculated using the natural population analysis (NPA) method [74]. Solvation effect has been modeled in water using the polarized continuum model (PCM) of Tomasi et al. [75-78] at the B3LYP/6-31+G(d,p) level for all tautomers/rotamers.

\section{Results and Discussion}

3.1. Geometrical Aspects of Diphosphocytosine Tautomeric Forms. Geometry of the 16 tautomers and rotamers was optimized at four different levels. Optimized structures of the 16 diphosphocytosine tautomers (at MP4(SDQ)/6-31+G(d)) are presented in Figure 1. For the notations of the tautomers and rotamers of diphosphocytosine, we use PC1, PC2, PC3, ...16 for the sixteen forms. All structures with their notations and atomic numbering are shown in Figure 1. Structure geometrical parameters of all the 16 tautomers are listed in Table 1. Bond length changes among tautomers show the same trend as expected from formal bond orders. In tautomers PC2, PC3, PC11, and PC12, all CC and CP bond lengths are in the range characteristic for aromatic rings. C1-C2 bond length changes among tautomers depending on the amount of $\pi$-bond character the tautomer has. In tautomers PC2, PC3, PC11, and PC12 this bond distance is about $1.40 \AA$ while in the rest of the tautomers this distance increased as shown in Table 1. In all the dienol forms, the P3-C2 and P3C4 and also P5-C6 and P5-C4 distances are nearly similar while those for the other keto-enol and diketo forms show considerable differences of about $0.147 \AA$. This reflects the extent of conjugation and the increasing aromatic character of the six-membered ring. An inspection of the dihedral angles in Table 1 proves that all the tautomers/rotamers structures are nonplanar. It is reported that [79] results of electron correlation calculations (MP2/6-31G ${ }^{*}$ ) give nonplanar geometries for several nucleotide bases specifically, for cytosine, which showed a significant pyramidalization of the amino group from MP2/6-31G* calculations. Using enormous computer resources, a complete $\mathrm{MP} 2 / 6-31 \mathrm{G}^{* *}$ frequency calculation was carried out [80] for cytosine, confirming that the planar structure is a saddle point. Bond angles in the ring show quite dramatic changes between tautomers and rotamers, by up to more than $10^{\circ}$. Owing to the lack of polarization functions on hydrogens, geometry parameters of the latter are expected to show larger differences, but these less important parameters were not listed in.

In the dienol form of diphosphocytosine, there are three double bonds giving it the six $\pi$-electrons needed to gain its aromatic character as in case of benzene. The phosphorous atom has an additional lone pair of electrons but not involved in the conjugated system. Once the keto form is formed in the diphosphocytosine, one resonance form is lost as the phosphorus atom is strongly pyramidal in the keto forms and its lone pairs are no longer available for conjugation. The extent of pyramidalization emerges from the sum of bond angles around the phosphorus atom. An extra destabilization occurs upon forming the second keto tautomer. Accordingly, diketo form is accompanied by destruction of conjugated $\pi$ electrons system in the ring of the diphosphocytosine. In case of cytosine, on the other hand, formation of keto or diketo forms still keeps planarity at the nitrogen atoms where they still able to resonate with the adjacent double bonds. Aromaticity is lost in both cytosine and diphosphocytosine, but the number of resonance structures decreased in the case of the latter system. 

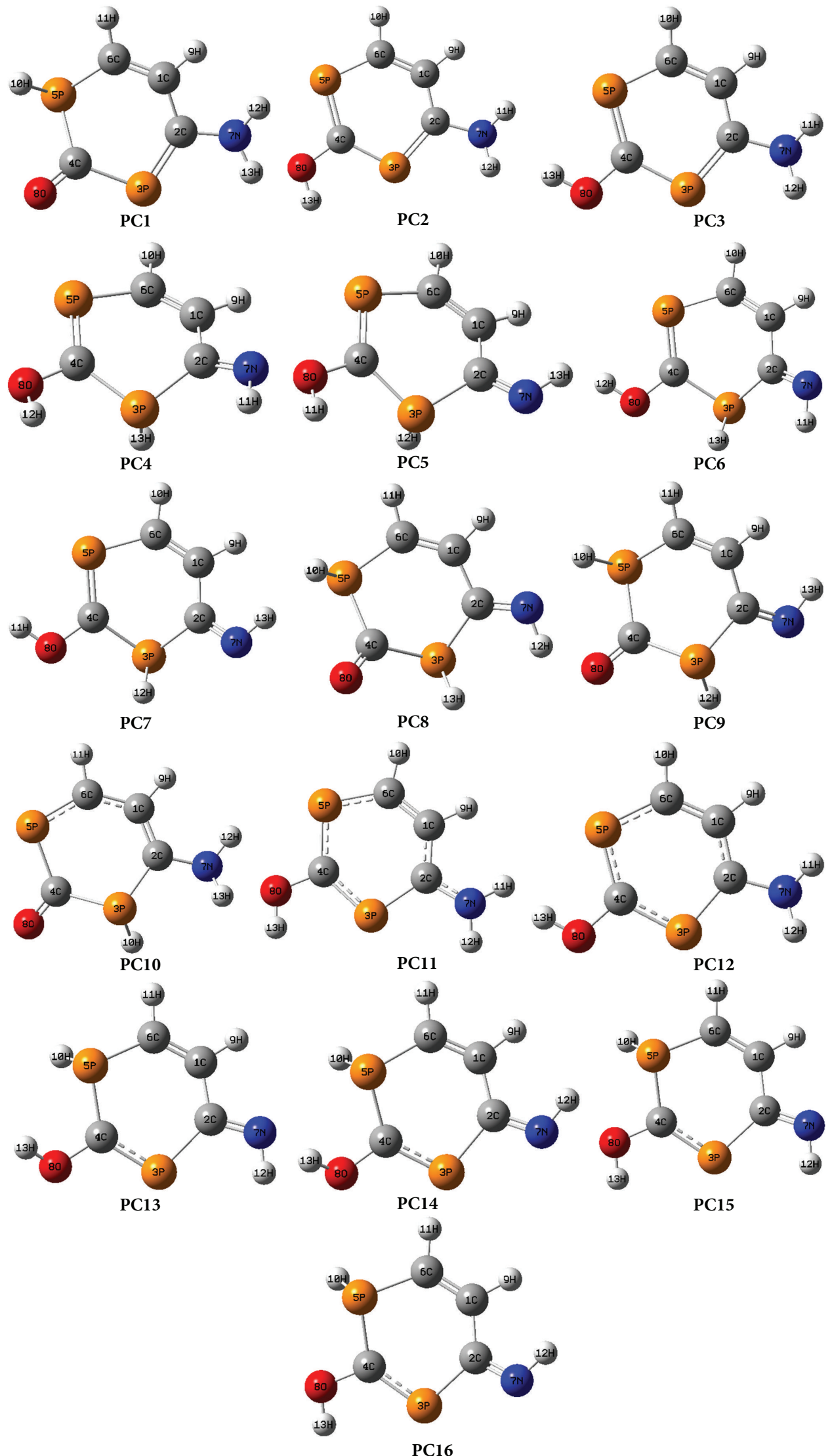

FIGURE 1: Optimized structures of the 16 PC isomers at MP4(SDQ)/6-31+G(d). 
TABLE 1: Computed geometrical data of the 16 diphosphocytosine tautomers at MP4(SDQ)/6-31+G(d).

\begin{tabular}{|c|c|c|c|c|c|c|c|c|c|c|c|c|c|c|c|c|}
\hline & PC1 & PC2 & PC3 & PC4 & PC5 & PC6 & PC7 & PC8 & PC9 & PC10 & PC11 & PC12 & PC13 & $\mathrm{PC14}$ & $\mathrm{C} 15$ & C16 \\
\hline$(1,2)$ & 1.469 & 403 & 1.409 & 1.472 & 1.475 & 1.476 & 1.479 & 1.478 & 1.487 & 1.364 & 1.403 & 1.409 & 477 & & 477 & 481 \\
\hline$(1,6)$ & & 1.39 & 35 & 1.351 & 51 & & & 19 & & & & & & & & 46 \\
\hline 9) & 93 & 1.093 & 1.094 & 91 & 1.094 & 91 & 93 & 1.091 & 93 & & 1.094 & & 91 & & 91 & 094 \\
\hline $\mathrm{R}(2,3)$ & 1.741 & 1.658 & 1.766 & 1.863 & 1.854 & 1.858 & 1.847 & 1.868 & 55 & 34 & 1.766 & 1.766 & 859 & 854 & 858 & 851 \\
\hline$(2,7)$ & 1.377 & 1.399 & 1.397 & 1.290 & 1.290 & 1.290 & 1.289 & 1.290 & & & 1.399 & 1.397 & .294 & .294 & 293 & 293 \\
\hline 34$)$ & 56 & 1.752 & 1.755 & 1.844 & 1.848 & 1.834 & 1.836 & 1.875 & 1.877 & 76 & 1.752 & 1.756 & 701 & .701 & 705 & 705 \\
\hline ,5) & 1.867 & 1.759 & 1.754 & 1.426 & 1.427 & 1.422 & 1.418 & 1.420 & 1.417 & 20 & 1.759 & 1.754 & 836 & 836 & 832 & 833 \\
\hline $\mathrm{R}(4,8)$ & 1.229 & 1.382 & 1.383 & 1.701 & 1.702 & 1.704 & 1.707 & 1.871 & 1.882 & 1.868 & 1.382 & 1.383 & .382 & 387 & 73 & .373 \\
\hline & 1.813 & 1.744 & 1.746 & 1.382 & 1.381 & 74 & 72 & 1.223 & 1.224 & 27 & 1.744 & & & & & 821 \\
\hline $\mathrm{R}($ & 1.420 & 1.092 & 1.092 & 1.831 & 1.831 & 1.829 & 1.829 & 1.834 & 1.831 & 1.708 & 1.092 & 1.092 & 426 & 426 & 423 & .423 \\
\hline $\mathrm{R}(6,11)$ & 1.091 & 1.016 & 1.016 & 1.092 & 1.092 & 1.091 & 1.092 & 1.421 & 1.421 & 1.094 & 1.016 & 1.016 & 1.091 & 1.091 & .091 & 091 \\
\hline & 1.014 & 1.016 & 1.016 & 1.028 & 1.031 & 1.028 & & 1.092 & & & & & & & & 030 \\
\hline & 1.015 & 0.977 & 0.977 & 0.976 & 0.976 & 78 & 0.978 & 1.028 & 1. & & 0.977 & 0.977 & 76 & 76 & 78 & .978 \\
\hline $\mathrm{A}(2,1,6)$ & 126.1 & 125.9 & 126.0 & 125.5 & 125.5 & 125.7 & 124.9 & 127.8 & 123.7 & 125.8 & 125.9 & 125.9 & 126.8 & 126.4 & 26.2 & 25.8 \\
\hline & 115.6 & 116.6 & 116.6 & 114.3 & 115.3 & & & .9 & & & & & & & & 14.9 \\
\hline A & 118.3 & 117.5 & 117.4 & 120.2 & 119.2 & 9 & 2 & 9.2 & 11 & 1 & 117.4 & 117.4 & 9.7 & .7 & 0.0 & 19.2 \\
\hline $\mathrm{A}(1,2,3)$ & 129.4 & 126.3 & 127.5 & 120.4 & 121.4 & 117.5 & 117.9 & 119.9 & 116.9 & 122.5 & 126.3 & 127.5 & 125.0 & 125.3 & 123.2 & 23.7 \\
\hline A & 112.8 & 117.6 & 116.8 & 118.1 & 124.6 & 117.5 & 124.8 & 116.6 & 124.9 & & 117.6 & 8 & 6 & 4 & & 23.1 \\
\hline & 117.9 & .9 & 5.6 & 12 & .9 & .5 & & .3 & & & & & & & & 12.9 \\
\hline $\mathrm{A}(2,3,4)$ & 101.6 & 103.7 & 102.5 & 102.9 & 102.6 & 101.6 & 100.7 & 100.1 & 101.0 & 102.4 & 103.7 & 102.6 & 102.8 & 101.8 & 102.9 & 101.9 \\
\hline A & 119.9 & 131.9 & 132.1 & 96.1 & 96.0 & 97.7 & & 97.6 & 98.0 & & & 132.1 & & 130.9 & 9.6 & 130.0 \\
\hline A & 119.3 & 116.3 & 4 & & 4 & & & & & & & & & & & 21.5 \\
\hline $\mathrm{A}(5,4,8)$ & 120.2 & 111.7 & 117.5 & 130.1 & 131.1 & 128.2 & 128.5 & 114.3 & 121.4 & 119.7 & 111.7 & 117.5 & 114.1 & 113.7 & 108.6 & 108.2 \\
\hline $\mathrm{A}(4$ & 100.3 & 100.7 & 101.7 & 113.7 & 113.2 & 108.9 & 109.1 & 122.4 & 119.8 & 119.4 & 100.6 & 101.7 & 102.2 & 101.8 & 100.8 & 100.5 \\
\hline $\mathrm{A}(4$, & 97.9 & 131.4 & 130.0 & 11 & 7 & 122.4 & & 122.8 & & & & & & & & 97.3 \\
\hline $\mathrm{A}(6,5,10)$ & 98.9 & 115.5 & 116.2 & 101.8 & 101.4 & 101.7 & 101.6 & 99.5 & 102.3 & 9 & 115.5 & 116.2 & 8.5 & 7.9 & .9 & 98.4 \\
\hline A & 124.8 & 113.1 & 113.7 & 131.5 & 131.5 & 130.9 & 130.7 & 95.9 & 95.6 & 134.6 & 113.1 & 113.7 & 126.9 & 126.4 & 126.5 & 126.0 \\
\hline ) & 118.4 & 115.3 & 7 & 11 & .5 & & & & & & & & & & & 18.7 \\
\hline 1) & 116.5 & 116.2 & 116.3 & .8 & .9 & .0 & 112.2 & 130.1 & 126.2 & & 116.1 & 116.3 & .1 & 114.6 & 14.5 & 14.9 \\
\hline $\mathrm{A}(2$ & 118.8 & 111.6 & 111.9 & 111.4 & 110.4 & 112.0 & 110.7 & 116.9 & 118.4 & 115.2 & 111.6 & 111.8 & .4 & 110.6 & 1.5 & 110.7 \\
\hline $\mathrm{A}(4$, & 118.5 & 110.6 & 109.9 & 110.3 & 110.2 & 2 & 4 & 9 & 8 & 5 & .5 & 10 & .9 & 8 & .4 & 10.2 \\
\hline $\mathrm{D}(6,1,2,3)$ & 114.4 & 0.1 & -0.1 & 24.8 & 23.7 & & & 112.3 & & & & & & & & 27.4 \\
\hline $\mathrm{D}(6,1,2,7)$ & -18.9 & 176.7 & 176.7 & 159.5 & 160.2 & 158.8 & -155.1 & 14.6 & -45.5 & -7.8 & -176.7 & 176.7 & -165.5 & -161.3 & -160.6 & -157.9 \\
\hline $\mathrm{D}(9,1,2,3)$ & 162.8 & -179.2 & -179.3 & -158.3 & -158.5 & -154.7 & -151.5 & -169.5 & 142.2 & 174.7 & 179.2 & -179.3 & -163.1 & -158.7 & -156.6 & -153.7 \\
\hline $\mathrm{D}(9,1,2,7)$ & 161.9 & -2.7 & -2.6 & 17.5 & 17.5 & 17.7 & 21.5 & -167.7 & 135.2 & 172.3 & & & & 17.7 & 17.9 & 21.0 \\
\hline $\mathrm{D}(2,1$ & -16.9 & -0.4 & -0.5 & 3.2 & 1.8 & 3 & 2 & 8.1 & -37.1 & -5.2 & 0.4 & -0.5 & 44 & 3.4 & 5.9 & 4.9 \\
\hline $\mathrm{D}(2,1,6,11)$ & -5.4 & 179.9 & 179.9 & 177.5 & 177.5 & 177.9 & 177.4 & -4.5 & -7.9 & -11.7 & 9 & 179.9 & 178.3 & 177.8 & 177.7 & 177.5 \\
\hline $\mathrm{D}(9,1,6,5)$ & -179.2 & 178.9 & 178.8 & -173.6 & -175.9 & -172.4 & -174.1 & 178.8 & -178.4 & & -178.9 & 178.7 & -174.4 & -175.6 & -172.5 & -173.9 \\
\hline $\mathrm{D}(9,1,6,11)$ & 174.4 & -0.8 & -0.8 & 0.8 & -0.1 & 1.6 & 0.8 & 177.9 & 171.4 & 168.2 & 8 & -0.8 & -0.6 & -1.2 & -0.7 & -1.4 \\
\hline $\mathrm{D}(1,2,3,4)$ & 0.5 & 0.2 & 0.5 & -29.8 & -26.7 & -41.3 & -43.4 & 13 & 9 & -8.3 & -0.2 & 0 & -15.7 & -18.9 & -22.2 & -23.6 \\
\hline & 3.9 & -176.3 & -176.3 & & 71.2 & -140.4 & -142.9 & -39.2 & & & & -176.3 & & 164.3 & 163.5 & 161.2 \\
\hline $\mathrm{D}(1,2,7,12)$ & -177.9 & 27.9 & 28.6 & 154.5 & 156.8 & 146.9 & 143.0 & -136.9 & 150.4 & & -27.9 & & -179.2 & 10 & -179.0 & 1.4 \\
\hline $\mathrm{D}(3,2,7,12)$ & 21.1 & 161.3 & 162.9 & -106.6 & -105.2 & 47.8 & 43.6 & 145.2 & -134.3 & -150.2 & -161.3 & 162.9 & -2.5 & 177.9 & -4.3 & 176.6 \\
\hline $\mathrm{D}(2,3,4,5)$ & 167.7 & -155.1 & -154.3 & 178.8 & -0.9 & 179.8 & -0.2 & 47.6 & -36.6 & -50.8 & 155.1 & -154.1 & -5.5 & -5.8 & -6.5 & -7.3 \\
\hline $\mathrm{D}(2,3,4,8)$ & -157.3 & -21.8 & -19.9 & -5.5 & 175.4 & -8.4 & 172.9 & -179.8 & -0.9 & & 21.8 & -19.9 & 177.3 & 176.8 & 179.3 & 179.3 \\
\hline $\mathrm{D}(3,4,5,6)$ & -10.7 & -0.3 & -0.5 & 14.9 & 11.4 & 33.1 & 33.2 & -4.1 & -173.2 & 150.9 & 3 & -0.6 & 20.2 & 22.7 & 26.9 & 28.6 \\
\hline $\mathrm{D}(3,4,5,10)$ & 31.3 & -179.9 & 179.9 & -165.9 & -168.3 & -153.9 & -153.9 & 58.7 & -18.3 & -160.2 & 179.9 & 179.8 & 120.4 & 122.3 & 127.4 & 128.6 \\
\hline $\mathrm{D}(8,4,5,6)$ & -157.3 & & & -83.1 & -86.4 & 132.5 & 132.7 & -129.5 & 161.9 & -26.8 & & & -162.5 & -159.9 & -158.3 & -157.3 \\
\hline $\mathrm{D}(8,4,5,10)$ & -46.8 & 179.8 & 179.8 & 96.0 & 93.9 & -54.5 & -54.4 & 157.6 & -117.7 & -44.4 & -179.8 & 179.8 & -62.3 & -60.3 & -57.8 & -57.3 \\
\hline $\mathrm{D}(3,4$, & -147.4 & -0.9 & 179.4 & 3.8 & 5.5 & -10.1 & -9.4 & -30.6 & 62.6 & 142.1 & 1.0 & 179.4 & 158.0 & 151.8 & 0.2 & 0.1 \\
\hline & 141.9 & 179.3 & -0.3 & -175.3 & -174.8 & 177.8 & 178.5 & -50.1 & -17.0 & -144.6 & -179.3 & -0.3 & -19.7 & -26.1 & -175.1 & -174.6 \\
\hline $\mathrm{D}(4,5,6,1)$ & 41.3 & 0.3 & 0.4 & 18.6 & 16.7 & -173.9 & -173.8 & -149.6 & -117.3 & 41.9 & -0.2 & 0.4 & -20.8 & -22.5 & -28.4 & -28.9 \\
\hline $\mathrm{D}(4,5,6,11)$ & 34.5 & 179.9 & 179.9 & -162.2 & -163.1 & -0.6 & -0.4 & 138.1 & 162.7 & 31.2 & -179.9 & 179.9 & 165.2 & 162.9 & 159.7 & 158.2 \\
\hline
\end{tabular}


TABLE 2: Thermodynamic parameters $(\mathrm{kcal} / \mathrm{mol})^{\mathrm{a}}$ for diphosphocytosine tautomers/rotamers at different levels in gas phase.

\begin{tabular}{|c|c|c|c|c|c|c|c|c|c|c|c|c|c|}
\hline \multirow{2}{*}{ Species } & \multicolumn{4}{|c|}{ B3LYP } & \multicolumn{4}{|c|}{ M06-2X } & \multicolumn{4}{|c|}{ MP2 } & \multirow{2}{*}{$\begin{array}{c}\mathrm{MP} 4(\mathrm{SDQ})^{\mathrm{b}} \\
\Delta E_{0}\end{array}$} \\
\hline & $\Delta E_{0}$ & $\Delta E_{0}^{\mathrm{b}}$ & $\Delta H_{298}$ & $\Delta G_{298}$ & $\Delta E_{0}$ & $\Delta E_{0}^{\mathrm{b}}$ & $\Delta H_{298}$ & $\Delta G_{298}$ & $\Delta E_{0}$ & $\Delta E_{0}^{\mathrm{b}}$ & $\Delta H_{298}$ & $\Delta G_{298}$ & \\
\hline PC1 & 3.70 & 7.01 & 5.78 & 4.66 & 6.84 & 10.26 & 8.99 & 7.83 & 9.90 & 13.27 & 11.61 & 11.38 & 7.19 \\
\hline PC2 & 0.00 & 0.62 & 0.50 & 0.46 & 0.00 & 0.72 & 0.58 & 0.50 & 0.40 & 0.42 & 0.42 & 0.38 & 0.46 \\
\hline PC3 & 0.47 & 0.00 & 0.00 & 0.00 & 0.40 & 0.00 & 0.00 & 0.00 & 0.00 & 0.00 & 0.00 & 0.00 & 0.00 \\
\hline PC4 & 24.73 & 28.43 & 26.96 & 25.99 & 25.98 & 29.52 & 28.11 & 27.05 & 27.46 & 31.80 & 30.46 & 30.01 & 24.82 \\
\hline PC5 & 24.55 & 28.53 & 26.87 & 25.63 & 26.02 & 29.68 & 28.21 & 27.01 & 28.17 & 32.75 & 26.78 & 26.68 & 25.51 \\
\hline PC6 & 22.28 & 25.73 & 24.30 & 23.46 & 23.58 & 26.75 & 25.49 & 24.67 & 24.72 & 28.90 & 26.94 & 26.91 & 22.23 \\
\hline PC7 & 22.11 & 25.64 & 24.15 & 23.54 & 23.14 & 26.49 & 25.13 & 24.44 & 24.87 & 29.09 & 26.94 & 0.04 & 22.17 \\
\hline PC8 & 9.97 & 16.68 & 13.65 & 12.64 & 12.76 & 19.53 & 16.50 & 15.40 & 15.91 & 23.12 & 19.50 & 0.03 & 13.96 \\
\hline PC9 & 12.00 & 19.21 & 15.95 & 14.82 & 14.16 & 21.46 & 18.21 & 16.73 & 17.82 & 25.48 & 21.66 & 21.11 & 15.68 \\
\hline PC10 & 5.37 & 8.90 & 7.56 & 6.44 & 8.83 & 12.65 & 11.21 & 9.95 & 11.78 & 15.27 & 13.56 & 13.24 & 9.63 \\
\hline PC11 & 0.92 & 0.48 & 0.50 & 0.46 & 0.967 & 0.56 & 0.58 & 0.50 & 0.40 & 0.42 & 0.42 & 0.38 & 0.46 \\
\hline PC12 & 0.47 & 0.00 & 0.00 & 0.00 & 0.400 & 0.00 & 0.00 & 0.00 & 0.00 & 0.00 & 0.00 & 0.00 & 0.00 \\
\hline PC13 & 23.47 & 27.01 & 25.57 & 24.70 & 24.31 & 27.87 & 26.48 & 25.13 & 26.13 & 30.61 & 28.41 & 27.86 & 23.42 \\
\hline PC14 & 25.18 & 29.14 & 27.50 & 26.56 & 25.96 & 29.81 & 28.25 & 27.26 & 27.68 & 32.49 & 30.12 & 0.00 & 25.17 \\
\hline PC15 & 20.56 & 23.71 & 22.39 & 21.86 & 21.26 & 24.50 & 23.17 & 22.55 & 22.98 & 26.92 & 24.90 & 0.00 & 20.05 \\
\hline PC16 & 21.76 & 25.23 & 23.75 & 23.23 & 22.43 & 25.76 & 24.39 & 23.81 & 23.96 & 28.21 & 26.04 & 25.99 & 21.24 \\
\hline
\end{tabular}

${ }^{a}$ Corrected for zero-point energy and thermal energy; ${ }^{\mathrm{b}}$ uncorrected energy.

TABLE 3: NPA atomic charges at MP2/6-31+G(d).

\begin{tabular}{|c|c|c|c|c|c|c|c|c|c|c|c|c|c|c|c|c|}
\hline & PC1 & PC2 & PC3 & PC4 & PC5 & PC6 & PC7 & PC8 & PC9 & PC10 & PC11 & $\mathrm{PC} 12$ & PC13 & $\mathrm{PC} 14$ & PC15 & PC16 \\
\hline $\mathrm{C} 1$ & -0.327 & 0.343 & .338 & 0.267 & -0.311 & .265 & -0.308 & .267 & .302 & .443 & 43 & 338 & .227 & -0.267 & .245 & -0.283 \\
\hline $\mathrm{C} 2$ & -0.041 & -0.068 & -0.077 & -0.025 & -0.024 & -0.017 & -0.016 & -0.015 & -0.033 & 0.017 & -0.068 & -0.077 & -0.061 & -0.064 & -0.041 & -0.045 \\
\hline P3 & 0.393 & 0.503 & 0.584 & 0.594 & 0.657 & 0.680 & 0.704 & 0.580 & 0.624 & 0.613 & 0.503 & 0.584 & 0.578 & 0.668 & 0.475 & 0.559 \\
\hline $\mathrm{C} 4$ & 0.029 & -0.336 & -0.338 & -0.352 & -0.326 & -0.293 & -0.268 & 0.061 & 0.057 & 0.033 & -0.335 & -0.338 & -0.322 & -0.361 & -0.280 & -0.314 \\
\hline P5 & 0.636 & 0.615 & 0.531 & 0.640 & 0.605 & 0.517 & 0.485 & 0.621 & 0.625 & 0. & 0.614 & 0.531 & 0.669 & 0.667 & 0.713 & 0.711 \\
\hline C6 & -0.468 & -0.533 & -0.523 & -0.555 & -0.521 & -0.545 & -0.514 & -0 & 25 & 15 & -0.533 & -0.523 & -0 & -0.530 & -0.553 & -0.525 \\
\hline N7 & -0.893 & -0.903 & -0.904 & -0.646 & -0.655 & -0.683 & -0.690 & -0.675 & -0.663 & -0.896 & -0.903 & -0.904 & -0.676 & -0.671 & -0.677 & -0.677 \\
\hline O8 & -0.661 & -0.774 & -0.776 & -0.771 & -0.771 & -0.773 & -0.770 & -0.628 & -0.635 & -0.645 & -0.774 & -0.776 & -0.771 & -0.775 & -0.772 & -0.778 \\
\hline H9 & 0.234 & 0.232 & 0.232 & 0.256 & 0.237 & 0.257 & 0.239 & 0.262 & 0.248 & 0.233 & 0.232 & 0.232 & 0.259 & 0.239 & 0.258 & 0.240 \\
\hline $\mathrm{H} 10$ & -0.021 & 0.259 & 0.261 & 0.254 & 0.254 & 0.257 & 0.256 & -0.019 & -0.022 & -0.013 & 0.259 & 0.261 & -0.037 & -0.036 & -0.029 & -0.030 \\
\hline H11 & 0.261 & 0.414 & 0.413 & 0.373 & 0.517 & 0.367 & 0.522 & 0.261 & 0.261 & 0.262 & 0.414 & 0.413 & 0.261 & 0.260 & 0.259 & 0.258 \\
\hline H12 & 0.421 & 0.419 & 0.421 & 0.515 & -0.025 & 0.523 & -0.006 & 0.371 & -0.003 & 0.423 & 0.419 & 0.421 & 0.371 & 0.359 & 0.370 & 0.361 \\
\hline H13 & 0.436 & 0.513 & 0.515 & -0.016 & 0.365 & -0.026 & 0.365 & -0.017 & 0.367 & 0.423 & 0.513 & 0.515 & 0.514 & 0.511 & 0.522 & 0.521 \\
\hline
\end{tabular}

3.2. Relative Energies and Thermodynamic Parameters of Tautomers. Since our major objective of this study was to obtain information on the relative stabilities of diphosphocytosine tautomers and rotamers, we tried to go as high as possible, with the level of theory and use both DFT and high correlation $a b$ initio MP2 and MP4(SDQ) methods. The results on the relative stabilities of diphosphocytosine tautomers and rotamers using different computational levels are listed in Table 2. For a better view, this is also shown in Figure 2. The results of the four computational methods are consistent with slight differences. The 16 diphosphocytosine tautomers and rotamers could be classified, on the basis of total relative energy, into three groups: (1) low-energy tautomers group containing four tautomers namely, PC2, PC3, PC11, and PC12. These tautomers: are those satisfying the aromaticity of the pyrimidine ring (the benzene-like structure), (2) moderate-energy tautomers group containing also four tautomers, PC1, PC8, PC9, and PC10. (3) high energy tautomers group containing the rest eight tautomers, PC4, PC5, PC6, PC7, PC13, PC14, PC15, and PC16. DFT methods predict PC2 to be the most stable lowest-energy tautomer. High correlation ab initio methods, on the other hand, predict the most stable is the hydroxy-amino form PC3. Energy difference is less than $0.50 \mathrm{kcal} / \mathrm{mol}$. The structural difference between the two tautomers/rotamers is the proximity of the positively charged $\mathrm{H}$ to the positively charged phosphorus atom. The same argument is applied to PC11 and PC12, where the positively charged $\mathrm{H}$ is repulsively interacting with P3 (0.503, Table 3) in PC11 and P5 (0.531, Table 3) in PC12. Previous studies suggest that the canonical amino-oxo structure is the most stable one [81]. PC5 is the most unstable highest-energy tautomer as predicted by 


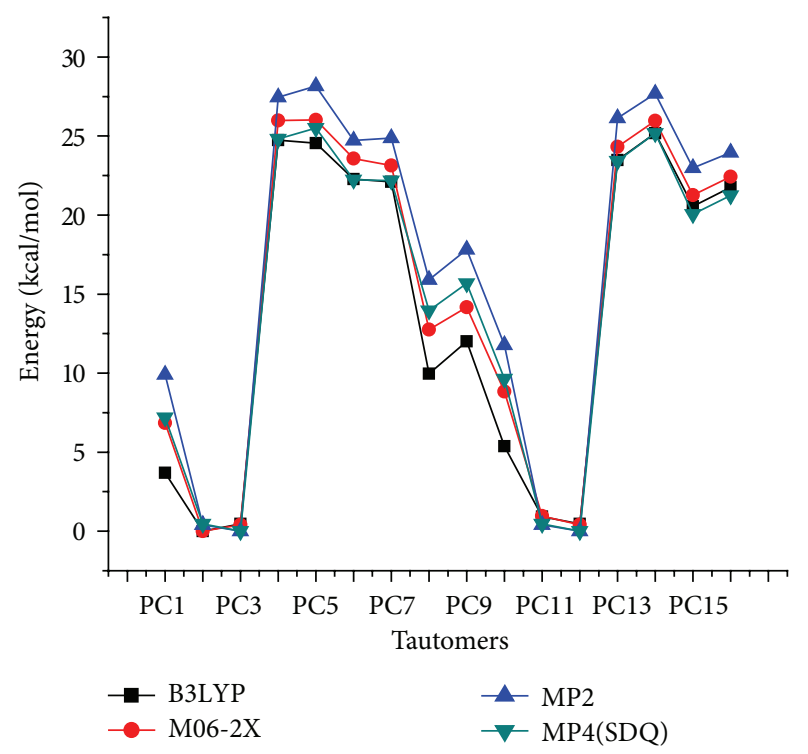

FIGURE 2: Relative energy of different diphosphocytosine tautomers at different levels.

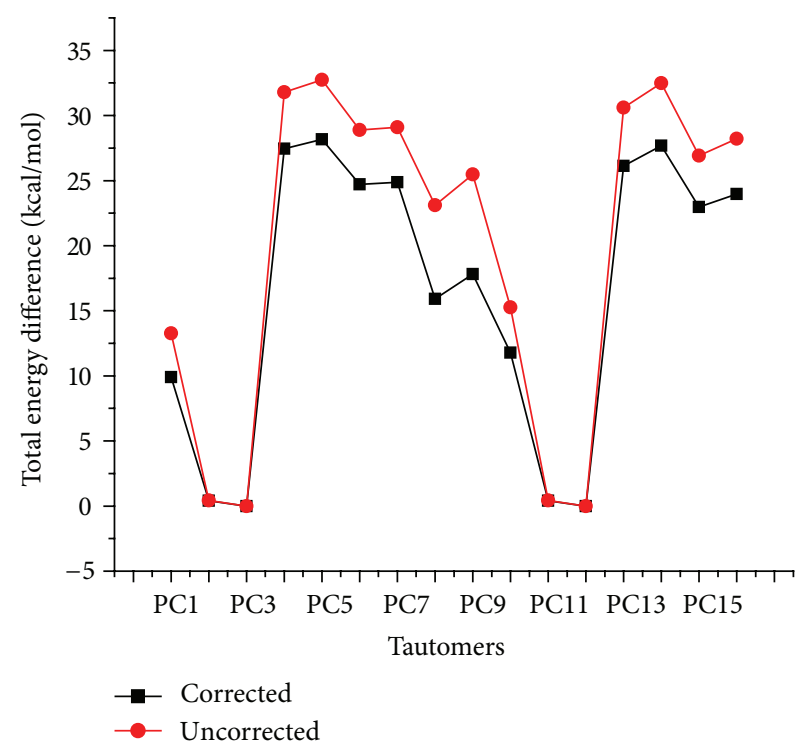

FIGURE 3: MP2 corrected for zero-point and thermal energy versus uncorrected one for all the 16 diphosphocytosine tautomers.

all methods. This could be due to the destruction of the aromaticity and also attributed to the repulsive interaction of the positively charged $\mathrm{H}$ and the great positive charge accommodated on P3 (0.657, Table 3). As could be seen from Table 2 that including zero-point energy and thermal energy correction has a considerable effect on the molecular energy. The corrected energy is lower than the uncorrected by about $4.0 \mathrm{kcal} / \mathrm{mol}$. Also, considering these corrections causes reordering of the tautomers stability. Figure 3 shows the MP2-corrected for zero-point and thermal energy versus uncorrected one for all the 16 diphosphocytosine tautomers. Based on the corrected energy, both B3LYP and M06-2X have

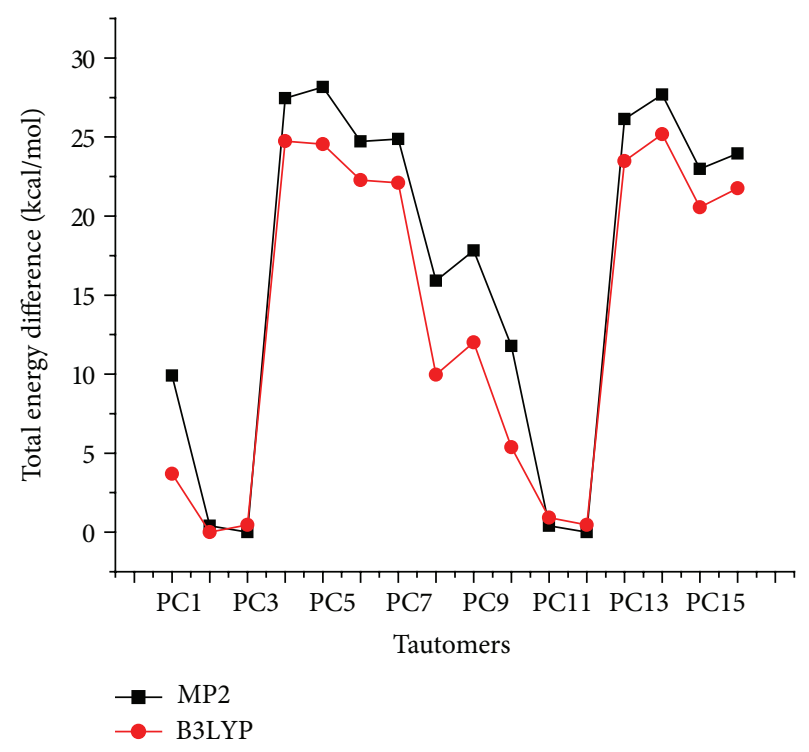

FIgURE 4: Tautomers' order by DFT and MP2 methods.

TABlE 4: Thermodynamic parameters for different tautomers $(\mathrm{kcal} / \mathrm{mol})$ at $\mathrm{B} 3 \mathrm{LYP} / 6-31+\mathrm{G}(\mathrm{d})$ in water.

\begin{tabular}{lcccc}
\hline & $\Delta E_{0}{ }^{\mathrm{a}}$ & $\Delta E_{0}{ }^{\mathrm{b}}$ & $\Delta H_{298}$ & $\Delta G_{298}$ \\
\hline PC1 & 3.531 & 0.658 & 2.021 & 22.773 \\
PC2 & 0.177 & 0.122 & 0.137 & 0.275 \\
PC3 & 0.000 & 0.000 & 0.000 & 0.000 \\
PC4 & 27.936 & 23.999 & 25.904 & 25.843 \\
PC5 & 28.035 & 23.887 & 25.919 & 25.612 \\
PC6 & 26.048 & 22.526 & 24.159 & 24.496 \\
PC7 & 26.193 & 22.510 & 24.229 & 24.550 \\
PC8 & 16.902 & 10.067 & 13.404 & 13.409 \\
PC9 & 19.178 & 11.994 & 15.528 & 15.411 \\
PC10 & 5.515 & 2.203 & 3.824 & 3.970 \\
PC11 & 0.177 & 0.126 & 0.137 & 0.287 \\
PC12 & 0.000 & 0.000 & 0.000 & 0.000 \\
PC13 & 25.953 & 22.167 & 23.990 & 24.103 \\
PC14 & 26.648 & 22.727 & 24.617 & 24.804 \\
PC15 & 24.025 & 20.722 & 22.223 & 22.721 \\
PC16 & 24.613 & 21.245 & 22.773 & 23.353 \\
\hline
\end{tabular}

${ }^{a}$ Uncorrected energy; ${ }^{b}$ corrected for zero-point and thermal energy.

the same order as PC2 $<$ PC3 $=$ PC12 $<$ PC11 $<$ PC1 $<$ PC10 $<$ PC8 < PC9 < PC15 < PC16 < PC7 < PC6 < PC13 < PC5 $\sim$ PC4 $\sim$ PC14. On the other hand, the relative stability order as predicted by $a b$ initio Moller Plesset MP2 and MP4(SDQ) is $\mathbf{P C} 3=\mathbf{P C 1 2}<\mathbf{P C 2}=\mathbf{P C 1 1}<\mathbf{P C 1}<\mathbf{P C 1 0}<\mathbf{P C 8}<\mathbf{P C 9}$ $<\mathrm{PC} 15<\mathrm{PC} 16<\mathrm{PC} 6 \sim \mathrm{PC} 7<\mathrm{PC13}<\mathrm{PC} 4 \sim \mathrm{PC} 14<$ PC5. However, MP4(SDQ) method shows slight differences like PC15 PC16 and PC4 < PC14 PC5. Figure 4 presents tautomers' order by DFT and MP2 methods. Enthalpy and free energy are consistent with the total energy as can be detected from Table 2. One of the electronic factors that affect the stability of the tautomers is the repulsion between the neighboring $-\mathrm{OH}$ and $-\mathrm{PH}$ or $-\mathrm{CH}$ groups, while the 
TABLE 5: NPA atomic charges at B3lyp/6-31+G(d)//B3lyp/6-31+G(d) PCM.

\begin{tabular}{|c|c|c|c|c|c|c|c|c|c|c|c|c|c|c|c|c|}
\hline & PC1 & PC2 & PC3 & PC4 & PC5 & PC6 & PC7 & PC8 & PC9 & PC10 & PC11 & PC12 & PC13 & PC14 & PC15 & PC16 \\
\hline $\mathrm{C} 1$ & -0.298 & 0.316 & -0.297 & -0.385 & .302 & -0.263 & -0.297 & 0.269 & -0.303 & -0.367 & -0.308 & -0.296 & -0.238 & -0.271 & -0.251 & -0.282 \\
\hline $\mathrm{C} 2$ & -0.147 & -0.106 & -0.152 & -0.057 & -0.052 & -0.056 & -0.057 & -0.049 & -0.061 & -0.061 & -0.126 & -0.151 & -0.096 & -0.088 & -0.067 & -0.073 \\
\hline P3 & 0.441 & 0.462 & 0.591 & 0.530 & 0.577 & 0.614 & 0.648 & 0.516 & 0.563 & 0.539 & 0.484 & 0.591 & 0.571 & 0.655 & 0.474 & 0.556 \\
\hline $\mathrm{C} 4$ & -0.066 & -0.375 & -0.403 & -0.361 & -0.369 & -0.348 & -0.338 & -0.007 & -0.011 & -0.033 & -0.383 & -0.403 & -0.374 & -0.402 & -0.347 & -0.369 \\
\hline P5 & 0.591 & 0.585 & 0.545 & 0.627 & 0.597 & 0.513 & 0.498 & 0.561 & 0.564 & 0.534 & 0.605 & 0.544 & 0.603 & 0.589 & 0.647 & 0.645 \\
\hline C6 & -0.495 & -0.559 & -0.568 & -0.158 & -0.526 & -0.536 & -0.521 & -0.515 & -0.517 & -0.587 & -0.567 & -0.568 & -0.535 & -0.515 & -0.530 & -0.516 \\
\hline N7 & -0.819 & -0.835 & -0.846 & -0.585 & -0.616 & -0.636 & -0.645 & -0.629 & -0.620 & -0.836 & -0.840 & -0.845 & -0.631 & -0.630 & -0.633 & -0.635 \\
\hline O8 & -0.562 & -0.702 & -0.706 & -0.662 & -0.692 & -0.697 & -0.693 & -0.535 & -0.539 & -0.545 & -0.698 & -0.705 & -0.698 & -0.707 & -0.699 & -0.704 \\
\hline H9 & 0.237 & 0.232 & 0.236 & 0.293 & 0.243 & 0.262 & 0.245 & 0.268 & 0.253 & 0.238 & 0.232 & 0.235 & 0.265 & 0.244 & 0.263 & 0.245 \\
\hline $\mathrm{H} 10$ & 0.010 & 0.263 & 0.267 & -0.157 & 0.261 & 0.264 & 0.263 & 0.013 & 0.011 & 0.018 & 0.262 & 0.2665 & -0.003 & 0.001 & 0.004 & 0.003 \\
\hline H11 & 0.266 & 0.420 & 0.412 & 0.379 & 0.508 & 0.363 & 0.511 & 0.267 & 0.266 & 0.266 & 0.415 & 0.411 & 0.266 & 0.264 & 0.264 & 0.263 \\
\hline $\mathrm{H} 12$ & 0.415 & 0.428 & 0.417 & 0.507 & 0.011 & 0.512 & 0.025 & 0.366 & 0.029 & 0.415 & 0.421 & 0.417 & 0.365 & 0.355 & 0.365 & 0.357 \\
\hline $\mathrm{H} 13$ & 0.427 & 0.504 & 0.506 & 0.029 & 0.361 & 0.006 & 0.361 & 0.012 & 0.363 & 0.418 & 0.502 & 0.506 & 0.506 & 0.504 & 0.510 & 0.511 \\
\hline
\end{tabular}

other factor is the attraction between the $\mathrm{O}-\mathrm{H}$ or $\mathrm{P}-\mathrm{H}$ bonds and the lone pair of the neighboring phosphorous or oxygen atoms. Another factor is the attractive interaction between the $\mathrm{O}-\mathrm{H}$ or $\mathrm{P}-\mathrm{H}$ bonds, on one side, and the lone pair(s) of the adjacent $\mathrm{P}$ or $\mathrm{O}$ atoms, on the other one [82].

The amino $\mathrm{N}$ accommodates the highest negative charge (up to -0.904); then the $\mathrm{O}$ atom comes in the second place (up to -0.778). Positive charges are accommodated on the $\mathrm{P}$ and $\mathrm{H}$ atoms. Very little negative charge on $\mathrm{H}$ bonded to $\mathrm{P}$ atoms as appeared in PC4, PC6, and PC8. The values of the NPA charges at hydrogen atoms of -OH groups are larger than the values at the hydrogen atom of the $-\mathrm{CH}$ group (see Table 3). As a result, the repulsion between the neighboring $-\mathrm{OH}$ and $-\mathrm{CH}$ groups is stronger than the repulsion of the neighboring $-\mathrm{PH}$ and $-\mathrm{CH}$ groups.

3.3. Solvation Study. One of the most crucial factors determining the tautomer distribution in the biological media is the environment. Solvent preferentially stabilizes structures with localized charges. Solvation effect has been explored in water $(\varepsilon=78.54)$ using the polarized continuum model (PCM) at the B3LYP/6-31+G(d) level for all the 16 tautomers. Table 4 collects the relative energies for different tautomers/rotamers $(\mathrm{kcal} / \mathrm{mol})$ at $\mathrm{B} 3 \mathrm{LYP} / 6-31+\mathrm{G}(\mathrm{d})$ in water. In water, the most stable diphosphocytosine tautomers are PC3 and PC12 and the most unstable tautomers/rotamers are PC4 and PC5. As seen from Table 4, the relative stabilities in water go in the order PC3 $\sim$ PC12 $\sim$ PC2 $\sim$ PC11 $<$ PC1 $<\mathrm{PC10}<\mathrm{PC} 8<\mathrm{PC} 9<\mathrm{PC} 15 \sim \mathrm{PC16}<\mathrm{PC13}<\mathrm{PC6} \sim$ PC7 $\sim$ PC14 $<$ PC4 PC5 at B3LYP/6-31+G(d) (PCM/water). This order is slightly different from that predicted at the same level in gas phase $(\varepsilon=1)$. For example, PC3 $\sim$ PC12 PC2 PC11. This result is easily understandable on the basis of the calculated dipole moment of these tautomers. Polar tautomers/rotamers are favored in polar solvents.

The NPA charges computed for tautomers/rotamers geometry optimized in water are given in Table 5.

The NPA charges computed for tautomers/rotamers geometry optimized in water are generally smaller than those computed for tautomers/rotamers optimized in gas phase. This is understandable as a role of the high dielectric constant solvent, water. The amino $\mathrm{N}$ accommodates the highest negative charge (up to -0.846 ), then the $\mathrm{O}$ atom comes in the second place (up to -0.707). Positive charges are accommodated on the $\mathrm{P}$ and $\mathrm{H}$ atoms. Very little negative charge on $\mathrm{H}$ bonded to $\mathrm{P}$ atoms as appeared in PC4, PC6, and PC8. The values of the NPA charges at hydrogen atoms of $\mathrm{OH}$ groups are larger than the values at the hydrogen atom of the $-\mathrm{CH}$ group (see Table 5). As a result, the repulsion between the neighboring $-\mathrm{OH}$ and $-\mathrm{CH}$ groups is stronger than the repulsion of the neighboring $-\mathrm{PH}$ and $-\mathrm{CH}$ groups.

\section{Summary}

On the basis of the present theoretical study, we may confirm the following conclusions.

(i) We studied for the first time 16 tautomers/rotamers of diphosphocytosine by four computational methods. Some of these tautomers/rotamers are isoenergetic although they have different structure.

(ii) From the total energy point of view, the 16 tautomers/rotamers are categorized into three main groups. These are low-energy difference group, moderate-energy difference group, and high-energy difference group.

(iii) PC3 and PC12 are the most stable tautomers/ rotamers.

(iv) Our systematic calculations show that the energy difference between components of a rotamer pair is very stable, independent of the level of theory. This leads to the important conclusion that besides the dominant PC3 form, its pair PC2 may lie not higher than $\sim 0.4 \mathrm{kcal} \mathrm{mol}^{-1}$; therefore, any experimental study should consider this possibility when evaluating spectroscopic experimental studies.

(v) Benzene-like structures are the most stable tautomers/rotamers. 
(vi) Charge is distributed on the ring atoms; -ve charges are on $\mathrm{N}$ and $\mathrm{O}$, while +ve charges on $\mathrm{P}$ and $\mathrm{H}$.

(vii) Solvation does not affect the order significantly; PC3 $\sim$ PC12 $\sim$ PC2 $\sim$ PC11 $<$ PC1 $<$ PC10 $<$ PC8 $<$ PC9 $<$ PC15 PC16 $<$ PC13 < PC6 PC7 PC14 < PC4 PC5.

\section{Acknowledgment}

This work was done at the Vienna Supercomputer Centre of the University of Vienna, Austria.

\section{References}

[1] J. March, Advanced Organic Chemistry, Reaction, Mechanism and Structure, John Wiley \& Sons, New York, NY, USA, 4th edition, 1993.

[2] J. Elguero, C. Marzin, A. R. Katritzky, and P. Linda, The Tautomerism of Heterocycles, Advances in heterocyclic chemistry: Supplement I, Academic Press, 1976.

[3] M. Dreyfus, O. Bensaude, G. Dodin, and J. E. Dubois, “Tautomerism in cytosine and 3-methylcytosine. A thermodynamic and kinetic study," Journal of the American Chemical Society, vol. 98, no. 20, pp. 6338-6349, 1976.

[4] R. Stolarski, M. Remin, and D. Shugar, "Studies on prototropic tautomerism in neutral and monoanionic forms of pyrimidines by nuclear magnetic resonance spectroscopy," Zeitschrift Für Naturforschung C, vol. 32, no. 5, pp. 894-900, 1977.

[5] J. Lin, C. Yu, S. Peng et al., "Ultraviolet photoelectron studies of the ground-state electronic structure and gas-phase tautomerism of hypoxanthine and guanine," The Journal of Physical Chemistry, vol. 84, no. 9, pp. 1006-1012, 1980.

[6] R. S. Norton, R.P. Gregson, and R.J. J. Quinn, “13 C n.m.r. spinlattice relaxation time measurements determining the major tautomer of 1-methylisoguanosine in solution," Journal of the Chemical Society, Chemical Communications, pp. 339-341, 1980.

[7] M. J. Nowak, K. Szczepaniak, A. Barski, and D. Shugar, "Spectroscopic studies on vapour phase tautomerism of natural bases found in nucleic acids," Zeitschrift fur Naturforschung, vol. 33, no. 11-12, pp. 876-883, 1978.

[8] P. O. LÖwdin, "Quantum genetics and the aperiodic solid: some aspects on the biological problems of heredity, mutations, aging, and tumors in view of the quantum theory of the DNA molecule," Advances in Quantum Chemistry, vol. 2, pp. 213-360, 1966.

[9] P. O. LÖwdin, Quantum Genetics and Aperiodic Solids, Preprint No 32. Quantum Theory Project for Research in Atomic, Molecular and Solid state, Chemistry and Physics, University of Florida, Gainesville, Fla, USA, 1962.

[10] J. Leszczynski, Ed., Computational Molecular Biology, vol. 8 of Theoretical and Computational Chemistry Book Series, Elsevier, 1999.

[11] S. Kwiatkowski and J. Leszczynski, "An ab Initio quantummechanical study of tautomerism of purine, adenine and guanine," Journal of Molecular Structure, vol. 208, no. 1-2, pp. 35-44, 1990.

[12] J. Leszczynski, "The potential energy surface of guanine is not flat: an ab Initio study with large basis sets and higher order electron correlation contributions," Journal of Physical Chemistry A, vol. 102, no. 13, pp. 2357-2362, 1998.
[13] E. D. Radchenko, A. M. Plohotnichenko, G. G. Sheina, Blagoi, and $\mathrm{P}$. Yu, "ab Initio study of the prototropic tautomerism of cytosine and guanine and their contribution to spontaneous point mutations," Biophysics, vol. 28, p. 559, 1983.

[14] Szczepaniak and K. Szczepaniak M, "Matrix isolation infrared studies of nucleic acid constituents: Part 4. Guanine and 9methylguanine monomers and their keto-enol tautomerism," Journal of Molecular Structure, vol. 156, no. 1-2, pp. 29-42, 1987.

[15] E. Nir, C. Janzen, P. Imhof, K. Kleinermanns, and M. S. de Vries, "Guanine tautomerism revealed by UV-UV and IR-UV hole burning spectroscopy," Journal of Chemical Physics, vol. 115, no. 10, pp. 4604-4611, 2001.

[16] M. J. Nowak, L. Lapinski, and J. Fulara, "Matrix isolation studies of cytosine: the separation of the infrared spectra of cytosine tautomers," Spectrochimica Acta A, vol. 45, no. 2, pp. 229-242, 1989.

[17] W. Saenger, Principles of Nucleic Acid Structure, Springer, New York, NY, USA, 1994.

[18] T. Shimanouchi, M. Tsuboi, and Y. Kyogoku, "The structure and properties of biomolecules and biological systems," Advances in Chemical Physics, vol. 7, p. 435, 1964.

[19] R. C. Lord and G. J. Thomas Jr., "Raman spectral studies of nucleic acids and related molecules-I Ribonucleic acid derivatives," Spectrochimica Acta Part A, vol. 23, no. 9, pp. 2551-2591, 1967.

[20] G. Lauer, W. Schäfer, and A. Schweig, "Functional subunits in the nucleic acid bases uracil and thymine," Tetrahedron Letters, vol. 16, no. 45, pp. 3939-3942, 1975.

[21] D. Dougherty, K. Wittel, J. Meeks, and S. P. McGlynn, "Photoelectron spectroscopy of carbonyls. Ureas, uracils, and thymine," Journal of the American Chemical Society, vol. 98, no. 13, pp. 3815-3820, 1976.

[22] A. Padva, T. G. O'Donnell, and P. R. LeBreton, "UV photoelectron studies of biological pyrimidines: the valence electronic structure of methyl substituted uracils," Chemical Physics Letters, vol. 41, no. 2, pp. 278-282, 1976.

[23] M. Fujii, T. Tamura, N. Mikami, and M. Ito, "Electronic spectra of uracil in a supersonic jet," Chemical Physics Letters, vol. 126, no. 6, pp. 583-587, 1986.

[24] Y. Tsuchiya, T. Tamura, M. Fujii, and M. Ito, "Keto-enol tautomer of uracil and thymine," Journal of Physical Chemistry, vol. 92, no. 7, pp. 1760-1765, 1988.

[25] B. B. Brady, L. A. Peteanu, and D. H. Leavy, "The electronic spectra of the pyrimidine bases uracil and thymine in a supersonic molecular beam," Chemical Physics Letters, vol. 147, no. 6, pp. 538-543, 1988.

[26] M. Kubota and T. J. Kobayashi, "Electronic structure of uracil and uridine derivatives studied by photoelectron spectroscopy," Journal of Electron Spectroscopy and Related Phenomena, vol. 82, no. 1-2, pp. 61-70, 1996.

[27] D. Shugar and K. Szczepaniak, "Tautomerism of pyrimidines and purines in the gas phase and in low-temperature matrices, and some biological implications," International Journal of Quantum Chemistry, vol. 20, no. 2, pp. 573-585, 1981.

[28] M. Szczesniak, M. J. Nowak, H. Rostkowska, K. Szczepaniak, W. B. Person, and D. Shugar, "Matrix isolation studies of nucleic acid constituents," Journal of the American Chemical Society, vol. 105, no. 19, pp. 5969-5976, 1983.

[29] S. Chin, I. Scot, K. Szczepaniak, and W. B. Person, "Matrix isolation itudies of nucleic acid constituents," Journal of the American Chemical Society, vol. 106, pp. 3415-3422, 1984. 
[30] Y. D. Radchenko, G. G. Scheina, N. A. Smorygo, Blagoi, and P. Yu, "Experimental and theoretical studies of molecular structure features of cytosine," Journal of Molecular Structure, vol. 116, no. 3-4, pp. 387-396, 1984.

[31] R. D. Brown, P. D. Godfrey, D. McNaughton, and A. P. Pierlot, "Microwave spectrum of uracil," Journal of the American Chemical Society, vol. 110, no. 7, pp. 2329-2330, 1988.

[32] I. Kulakowska, M. Geller, B. Lesyng, K. L. Wierzchowski, and K. Bolewska, "Barrier to rotation and conformation of the $-\mathrm{NR}_{2}$ group in cytosine and its derivatives. Part II. Experimental and theoretical dipole moments of methylated cytosines," Biochimica Et Biophysica Acta, vol. 407, no. 4, pp. 420-429, 1975.

[33] B. B. Brady, L. A. Peteanu, and D. H. Levy, "The electronic spectra of the pyrimidine bases uracil and thymine in a supersonic molecular beam," Chemical Physics Letters, vol. 147, no. 6 , pp. $538-543,1981$.

[34] P. Beak and J. M. White, "Relative enthalpies of 1, 3-dimethyl2, 4-pyrimidinedione, 2, 4-dimethoxypyrimidine, and 4methoxy-1-methyl-1-2-pyrimidinone: estimation of the relative stabilities of two protomers of uracil," Journal of the American Chemical Society, vol. 104, no. 25, pp. 7073-7077, 1982.

[35] J. S. Kwiatkowski, R. J. Bartlett, and W. B. Person, "Contributions from electron correlation to the relative stabilities of the tautomers of nucleic acid bases," Journal of the American Chemical Society, vol. 110, no. 8, pp. 2353-2358, 1988.

[36] H. Basch, D. R. Garmer, P. G. Jasien, M. Krauss, and W. J. Stevens, "Electrical properties of nucleic acid bases," Chemical Physics Letters, vol. 163, no. 6, pp. 514-522, 1989.

[37] A. Les, L. Adamowicz, and R. J. Bartlett, "Relative stability of cytosine tautomers with the coupled cluster method and firstorder correlation orbitals," Journal of Physical Chemistry, vol. 93, pp. 4001-4005, 1989.

[38] I. R. Gould and I. H. Hillier, "Accurate Calculations of the OxoHydroxy Tautomers of UracilParaaa," Journal of the Chemical Society, Perkin Transactions 2, vol. 2, pp. 329-330, 1990.

[39] A. Les and L. Adamowic, "Theoretical ab Initio study of the protomeric tautomerism of 2-hydroxypyrimidine, 4hydroxypyrimidine, and their derivatives," Journal of Physical Chemistry, vol. 94, no. 18, pp. 7021-7032, 1990.

[40] P. G. Jasien and G. Fitzgerald, "Molecular dipole moments and polarizabilities from local density functional calculations: Application to DNA base pairs," The Journal of Chemical Physics, vol. 93, no. 4, pp. 2554-2560, 1990.

[41] J. Leszczynśki, "Structure and properties of uracil and its sulfur analogs: a systematic study of basis set effects in Ab Initio SCF calculations," Physical Chemistry, vol. 40, supplement 18, pp. 921, 1991.

[42] A. R. Katritzky and M. Karelson, "Aml calculations of reaction field effects on the tautomeric equilibria of nucleic-acid pyrimidine and purine-bases and their 1-methyl analogs," Journal of the American Chemical Society, vol. 113, no. 5, pp. 1561-1566, 1991.

[43] J. Leszczynski, "Tautomerism of uracil: the final chapter? Fourth-order electron correlation contributions to the relative energies of tautomers," Journal of Physical Chemistry, vol. 96, no. 4, pp. 1649-1653, 1992.

[44] D. A. Estrin, L. Paglieri, and G. Corongiu, "A density functional study of tautomerism of uracil and cytosine," Journal of Physical Chemistry, vol. 98, no. 22, pp. 5653-5660, 1994.

[45] I. R. Gould, N. A. Burton, R. J. Hall, and I. H. Hillier, "Tautomerism in uracil, cytosine and guanine: a comparison of electron correlation predicted by $a b$ Initio and density functional theory methods," Journal of Molecular Structure, vol. 331, no. 1-2, pp. 147-154, 1995.

[46] L. Paglieri, G. Corongiu, and D. A. Estrin, "Solvent effects in density functional calculations of uracil and cytosine tautomerism," International Journal of Quantum Chemistry, vol. 56, no. 5, pp. 615-625, 1995.

[47] M. Monshi, K. Al-Farhan, S. Al-Resayes, A. Ghaith, and A. A. Hasanein, "Excited states dipole moments and polarizabilities of uracil and cytosine 5-halo derivatives," Spectrochimica Acta A, vol. 53, no. 14, pp. 2669-2677, 1997.

[48] S. X. Tian, C. F. Zhang, Z. J. Zhang, X. J. Chen, and K. Z. $\mathrm{Xu}$, "How many uracil tautomers there are? Density functional studies of stability ordering of tautomers," Chemical Physics, vol. 242, no. 2, pp. 217-225, 1999.

[49] S. I. Kawaharaa, T. Uchimarua, and M. Sekineb, “The hydrogen bond energy on mismatched base pair formation between uracil derivatives and guanine in the gas phase and in the aqueous phase," Journal of Molecular Structure, vol. 530, pp. 1109-2117, 2000.

[50] M. K. Shukla and J. Leszczynski, "Phototautomerism in Uracil: a quantum chemical investigation," Journal of Physical Chemistry A, vol. 106, no. 37, pp. 8642-8650, 2002.

[51] X. Li, L. Sanche, and M. D. Sevilla, "Dehalogenation of 5halouracils after low energy electron attachment: A density functional theory investigation," Journal of Physical Chemistry A, vol. 106, no. 46, pp. 11248-11253, 2002.

[52] M. Di Laudo, S. R. Whittleton, and S. D. Wetmore, "Effects of hydrogen bonding on the acidity of uracil," Journal of Physical Chemistry A, vol. 107, no. 48, pp. 10406-10413, 2003.

[53] M. Piacenza and S. Grimme, "Systematic quantum chemical study of DNA-base tautomers," Journal of Computational Chemistry, vol. 25, no. 1, pp. 83-98, 2004.

[54] Iwona Dabkowska, Janusz Rak, Maciej Gutowskia, J. Michael Nilles, S. T. Stokes, and K. H. Bowen, "Barrier-free intermolecular proton transfer induced by excess electron attachment to the complex of alanine with uracil," Journal of Chemical Physics, vol. 120, no. 13, 2004.

[55] X. Hu, H. Li, W. Liang, and S. Han, "Theoretical study of the proton transfer of uracil and (water) $\mathrm{n}(n=0-4)$ : Water stabilization and mutagenicity for uracil," Journal of Physical Chemistry B, vol. 108, no. 34, pp. 12999-13007, 2004.

[56] R. Zhang, A. Ceulemans, and Nguyen, "A theoretical study of Uracil and its tautomers in their lowest-lying triplet state," Molecular Physics, vol. 103, no. 6-8, pp. 983-994, 2005.

[57] X. Hu, H. Li, W. Liang, and S. Han, "Systematic study of the tautomerism of uracil induced by proton transfer. exploration of water stabilization and mutagenicity," Journal of Physical Chemistry B, vol. 109, no. 12, pp. 5935-5944, 2005.

[58] J. K. Wolken and F. Turecek, "Proton affinity of uracil: a computational study of protonation sites," Journal of the American Society For Mass Spectrometry, vol. 11, no. 12, pp. 1065-1071, 2000.

[59] V. Esposito, A. Randazzo, G. Piccialli, L. Petraccone, C. Giancola, and L. Mayol, "Effects of an 8-bromodeoxyguanosine incorporation on the parallel quadruplex structure [d(TGGGT)]4," Organic and Biomolecular Chemistry, vol. 2, no. 3, pp. 313-318, 2004.

[60] S. D. Wetmore, R. J. Boyd, and L. A. Eriksson, "A theoretical study of 5-halouracils: electron affinities, ionization potentials and dissociation of the related anions," Chemical Physics Letters, vol. 343, no. 1-2, pp. 151-158, 2001. 
[61] P. U. Civcir, "AM1 and PM3 studies of some thio analogues of pyrimidine bases in the gas and aqueous phases," Journal of Physical Organic Chemistry, vol. 14, no. 3, pp. 171-179, 2001.

[62] S. Denifl, S. Matejcik, B. Gstir et al., "Electron attachment to 5-chloro uracil," Journal of Chemical Physics, vol. 118, no. 9, pp. 4107-4114, 2003.

[63] W. Saenger and D. Suck, “The Relationship between hydrogen bonding and base stacking in crystalline 4-thiouridine derivatives," European Journal of Biochemistry, vol. 32, no. 3, pp. 473478, 1973.

[64] A. G. Lezius and K. H. Scheit, "Enzymatic synthesis of DNA with 4-thio-thymidine triphosphate as substitute for dTTP," European Journal of Biochemistry, vol. 3, no. 1, pp. 85-94, 1967.

[65] K. H. Scheit and E. Gartner, "Über die Eigenschaften von polynucleotiden, welche uridin und 4-thiouridin enthalten," Biochimica Et Biophysica Acta, vol. 182, no. 1, pp. 10-16, 1969.

[66] E. M. Gottschalk, E. Kopp, and A. G. Lezius, "A synthetic DNA with unusual base-pairing," European Journal of Biochemistry, vol. 24, no. 1, pp. 168-182, 1971.

[67] T. M. El-Gogary and A. M. El-Nahas, "Origin of reverse stability of diphosphouracil tautomers compared to their analogue uracil: DFT and ab Initio study," Journal of Molecular Structure, vol. 851, no. 1-3, pp. 54-62, 2008.

[68] A. F. Jalbout, B. Trzaskowski, Y. Xia et al., "Structures, stabilities and tautomerizations of uracil and diphosphouracil tautomers," Chemical Physics, vol. 332, no. 2-3, pp. 152-161, 2007.

[69] M. J. Frisch, G. W. Trucks, H. B. Schlegel et al., Gaussian 09, Revision A. 1, Gaussian Inc., Wallingford, Conn, USA, 2009.

[70] A. D. J. Becke, "Density-functional thermochemistry. III. The role of exact exchange," Chemical Physics, vol. 98, no. 7, pp. 5648-5652, 1993.

[71] C. Lee, W. Yang, and R. G. Parr, "Development of the ColleSalvetti correlation-energy formula into a functional of the electron density," Physical Review B 37, pp. 785-789, 1988.

[72] P. J. Stephens, F. J. Devlin, C. F. Chabalowski, and M. J. Frisch, " $a b$ Initio calculation of vibrational absorption and circular dichroism spectra using density functional force fields," Journal of Physical Chemistry, vol. 98, no. 45, pp. 11623-11627, 1994.

[73] G. A. Zhurko and D. A. Zhurko, ChemCraft version 1. 5, 2005.

[74] A. E. Reed, R. B. Weinstock, and F. Weinhold, "Natural population analysis," The Journal of Chemical Physics, vol. 83, no. 2, pp. 735-746, 1985.

[75] S. Miertus, E. Scrocco, and J. Tomasi, "Electrostatic interaction of a solute with a continuum. A direct utilizaion of $a b$ Initio molecular potentials for the prevision of solvent effects," Journal of Chemical Physics, vol. 55, no. 1, pp. 117-129, 1981.

[76] J. Tomasi and M. Persico, "Molecular interactions in solution: An overview of methods based on continuous distributions of the solvent," Chemical Reviews, vol. 94, no. 7, pp. 2027-2094, 1994.

[77] R. Cammi and J. Tomasi, "Remarks on the use of the apparent surface charges/ASC methods in solvation problems: iterative versus matrix-inversion procedures and the renormalization of the apparent charges," Journal of Computational Chemistry, vol. 16, pp. 1449-1458, 1995.

[78] M. Cossi, V. Barone, R. Cammi, and J. Tomasi, "ab Initio study of solvated molecules: A new implementation of the polarizable continuum model," Chemical Physics Letters, vol. 255, no. 4-6, pp. 327-335, 1996.

[79] J. Sponer and P. Hobza, "Nonplanar Geometries of DNA Bases. ab Initio Second-Order Moeller-Plesset Study," Journal of Physical Chemistry, vol. 98, no. 12, pp. 3161-3164, 1994.
[80] E. L. Stewart, C. K. Foley, N. L. Allinger, and J. P. Bowen, "ab Initio calculations with electronic correlation (MP2) on the nucleic acid bases and their methyl derivatives," Journal of the American Chemical Society, vol. 116, no. 16, pp. 7282-7286, 1994.

[81] V. B. Delchev and M. V. Nenkova, "Theoretical Modeling of the Ground State Intramolecular Proton Transfer in Cytosine: DFT Level Study," Acta Chimica Slovenica, pp. 132-137, 2008.

[82] T. K. Ha, H. J. Keller, R. Gunde, and H. H. Gunthard, "Energy increment method based on quantum chemical results: a general recipe for approximative prediction of isomerization and tautomerization energies of pyrimidine and purine Nucleic acid bases and related compounds," Journal of Physical Chemistry A, vol. 103, no. 33, pp. 6612-6623, 1999. 

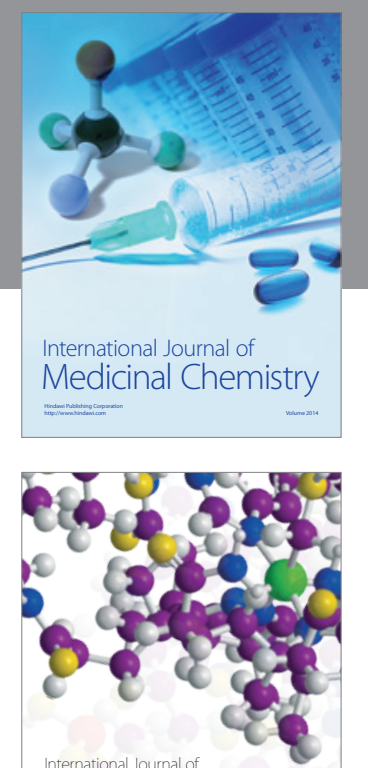

\section{Carbohydrate} Chemistry

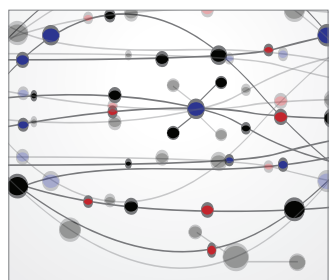

The Scientific World Journal
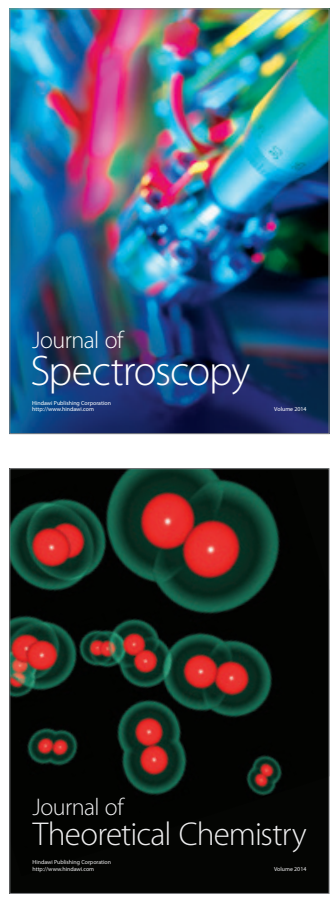
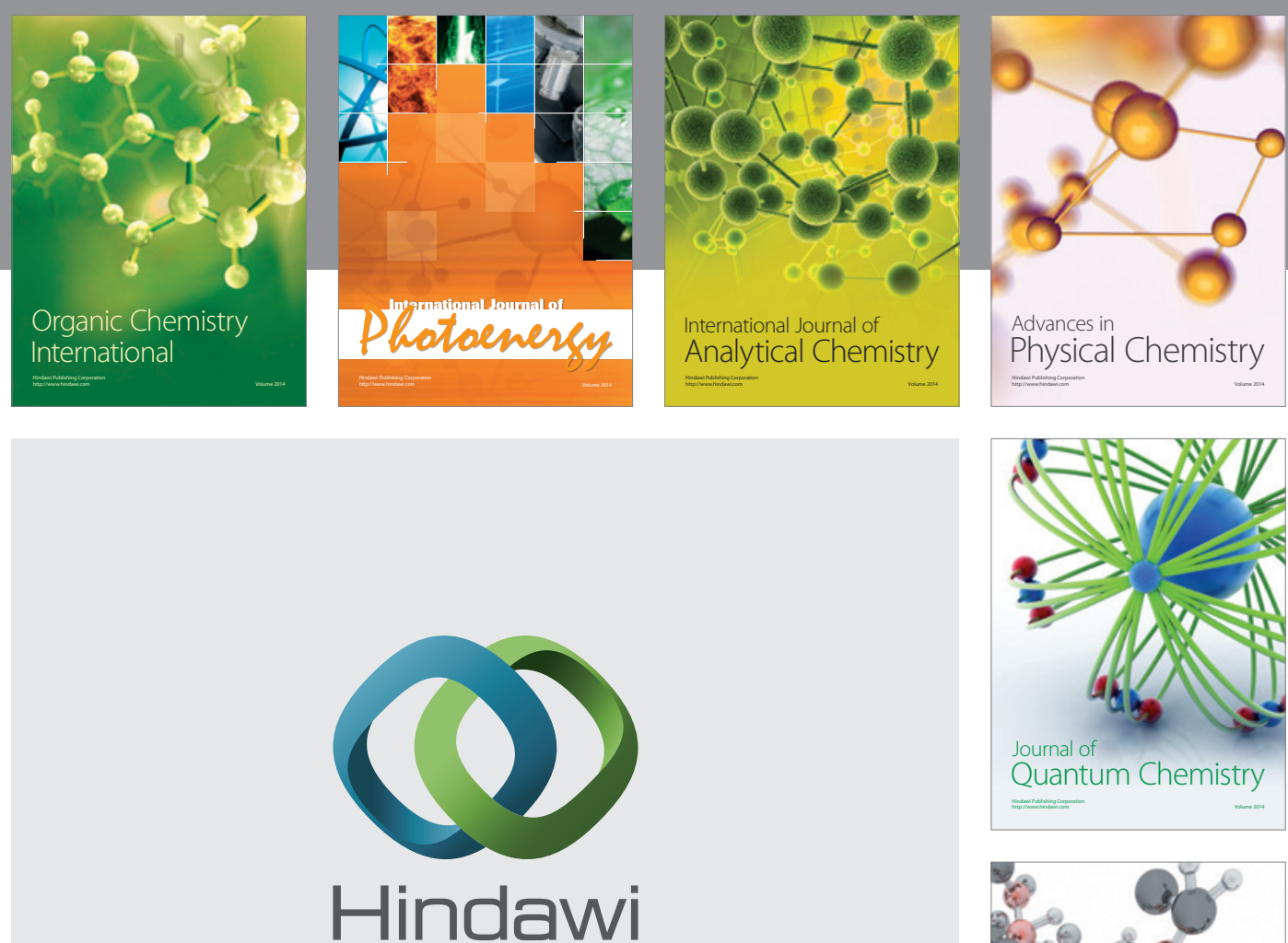

Submit your manuscripts at

http://www.hindawi.com

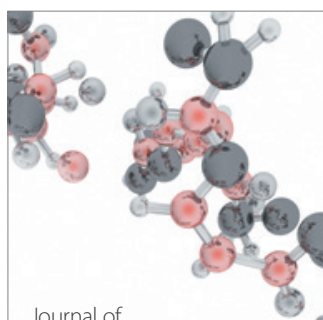

Analytical Methods

in Chemistry

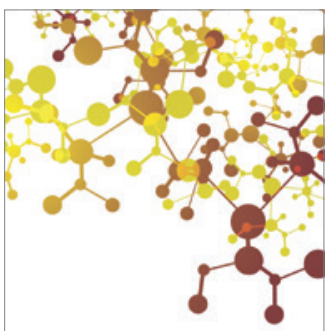

Journal of

Applied Chemistry

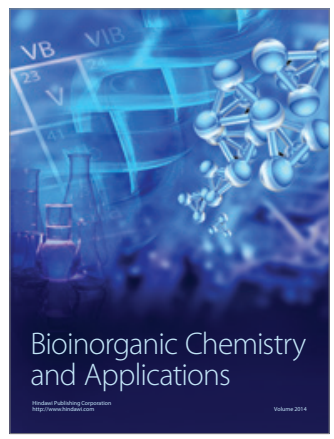

Inorganic Chemistry
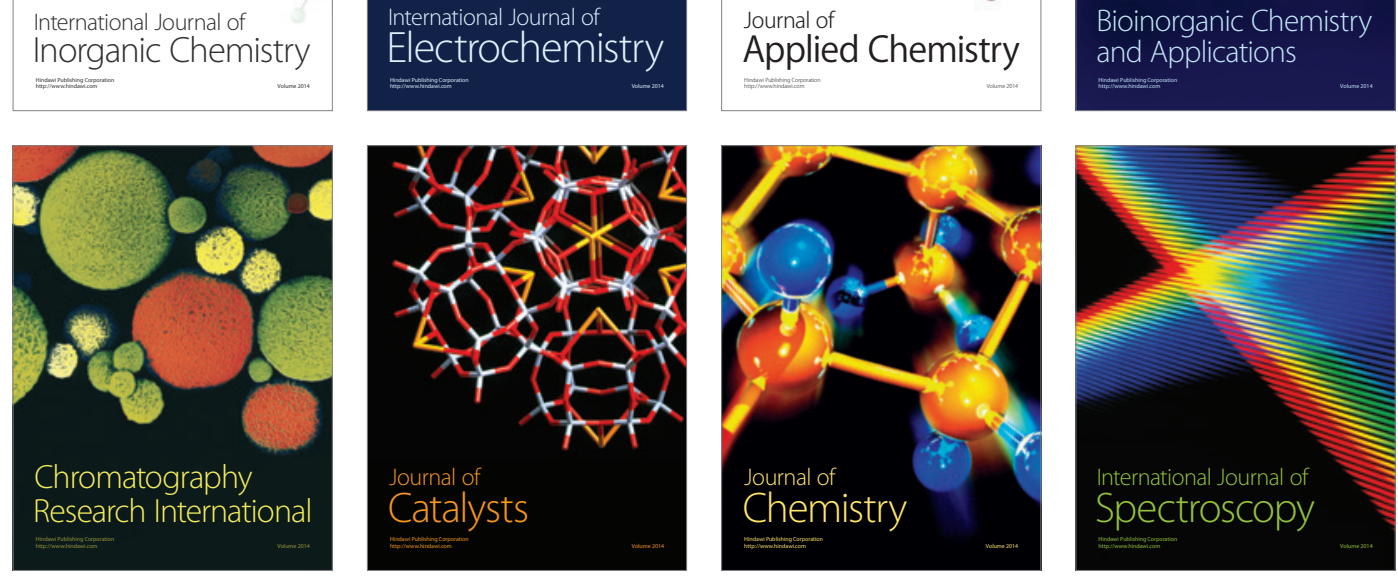